\title{
EXTRAÇÃO DO ÓLEO DA SEMENTE DA AMEIXA AMARELA (Eriobotrya japonica)
}

\author{
L. NAGI ${ }^{1}$, M. GABRIEL ${ }^{1}$, T. S. RIPPEL ${ }^{1}$, M. A. FIORI ${ }^{1}$, J. M. M. MELLO ${ }^{1}$, F. $^{2}$ \\ DALCANTON $^{1}$ \\ ${ }^{1}$ Universidade Comunitária da Região de Chapecó \\ E-mail para contato: lili_nagi@unochapeco.edu.br
}

\begin{abstract}
RESUMO - A ameixa amarela (Eriobotrya japonica) é uma fruta cítrica de origem asiática, cultivada no sul e sudeste do Brasil. As frutas contêm de 3 a 5 sementes que são consideradas resíduos industriais e o óleo presente nestas sementes apresenta elevados níveis de polifenóis, que ajudam a combater radicais livres, podendo se tornar uma possível aplicação na área alimentícia e química. Neste sentido, este trabalho teve como objetivo avaliar diferentes condições de extração do óleo presente na semente da ameixa amarela. A fruta madura foi colhida no município de Chapecó/Santa Catarina e as sementes foram retiradas manualmente e a extração foi realizada pelo método de Soxhlet. Através de um planejamento fatorial completo $2^{2}$, em duplicata, variou-se o tipo de solvente (hexano e etanol) e o tempo de extração (60 e $120 \mathrm{~min}$ ). Os resultados mostraram que apenas o tipo de solvente foi significativo, sendo que, o solvente mais eficaz foi o etanol extraindo $15 \%$ de óleo. O modelo matemático obtido foi preditivo e explica 99,16\% das respostas obtidas por ele. O solvente etanol, por ser oriundo de recursos renováveis, abre portas para futuras pesquisas na área de extração, em comparação com o solvente hexano, que pode deixar resíduos tóxicos nos óleos.
\end{abstract}

Palavras-chave: Extração, semente, resíduo industrial, óleo.

DOI: $10.5965 / 24473650312017009$

\section{INTRODUÇÃO}

Os óleos essenciais são importantes matérias-primas para diversos ramos industriais, pois possuem propriedades antissépticas, calmantes, relaxantes, descongestionantes além de efeito energético (GONSALVES, 1999; ALBRIGHT, 1998). A qualidade dos óleos depende de muitos fatores, sendo que o processo pelo qual a substância é obtida, o seu estado de maturidade e preservação e a sua fonte são fatores importantes (RICHARDS, 2015).

No Brasil a aplicação destes compostos se dá principalmente na indústria de perfumaria, bem como nas indústrias alimentícia, de produtos de limpeza, química e de medicamentos (SOUZA, MEIRA, 2010). Dentre a demanda de óleos essenciais extraídos de frutas cítricas no mundo, pode-se citar, a laranja (Citrus sinensis), o limão (Citrus limon), a lima destilada (Citrus aurantifolia), entre outras (BIZZO, HOVELL, REZENDE, 2009), porém a Eriobotrya japonica não é citada. 
A Eriobotrya japonica (Lindl.), pertencente à família Rosaceae é uma fruta cítrica conhecida popularmente no Brasil como nêspera, ameixa-de-inverno ou ameixa amarela. É uma fruta de origem asiática, sendo cultivada na China, Japão, Estados Unidos (Califórnia e Flórida), México, América do Sul, entre outros (BAJAJ, 1991). Sua árvore possui de 6 a 9 metros de altura e possuem cachos que comportam de 4 a 30 frutos. Cada uma delas possui coloração de verde até amarelo-alaranjado ou alaranjado, conforme o amadurecimento. No seu interior são abrigados de 3 a 5 sementes de tamanho médio que são responsáveis por aproximadamente $1 / 4$ do peso total da fruta (SMALL, 2012). As sementes são descartadas e o consumo se dá apenas da polpa da fruta.

A fruta tem ação antidiarréica, anti-hemorrágica, anti-inflamatória, antioxidante, antialérgica, antiviral e diurética; ela ainda possui hidratos de carbono, sais minerais (principalmente cálcio, fósforo e potássio), vitaminas A, C e do complexo B. Possui também fitonutrientes que ajudam na prevenção contra doenças (LIM, 2012). Segundo Hasegawa (2010), apresenta uma elevada concentração de pectina, o que favorece o processamento industrial na fabricação de doces e geleias. Suas folhas são ricas em óleos voláteis e vitamina B17. Suas sementes são ricas em amido (20\%), sendo um bom material para a produção de vinhos (BAJAJ, 1991).

Segundo Lim (2012) um alto nível de polifenóis foi encontrado no extrato etanoico de sementes de ameixa amarela. Os polifenóis são compostos derivados do benzeno e exercem funções como sequestro de radicais livres, os quais em excesso causam estresse oxidativo resultando em danos celulares (KOBA, 2007). Além disso, estes compostos eliminam os efeitos da lipoproteína de baixa densidade (LDL) oxidada, auxiliando desta maneira, na prevenção de infarto agudo do miocárdio, acidente vascular cerebral (AVC) ou mesmo aterosclerose se não suprimido (GIDLUND et al., 2008).

Porém toda a aplicação existente na indústria se dá apenas com o uso da polpa da fruta, não havendo alternativa para a semente a não ser o descarte. Por isso, o objetivo deste trabalho foi avaliar diferentes condições de extração do óleo presente na semente da ameixa amarela (Eriobotrya japonica) por via Soxhlet.

\section{MATERIAL E MÉTODOS}

Os ensaios de extração foram realizados nos laboratórios de Química Geral e de Operações Unitárias II da Universidade Comunitária da Região de Chapecó (UNOCHAPECÓ).

\subsection{Preparo da amostra}

Os frutos foram coletados no município de Chapecó-SC e selecionados em relação aqueles visualmente sadios, inteiros, sem deformações e maduros.

Após a seleção foi realizada a higienização dos frutos com água corrente e hipoclorito de sódio $(2 \% \mathrm{p} / \mathrm{p})$ por $60 \mathrm{~s}$. Separaram-se as sementes do fruto de forma manual. As sementes foram trituradas em liquidificador industrial (SpoluBenese do Brasil LTDA), por $120 \mathrm{~s}$ e colocadas em estufa (Nova Ética) à $80^{\circ} \mathrm{C}$, até peso constante, para retirar a umidade das sementes e tornar o processo de extração ser mais efetivo. Em seguida foi padronizada a granulometria das amostras secas em peneiras de 28 Mesh Tyler (BERTEL Industria Metalúrgica). 


\subsection{Extração}

Pesaram-se 3,00 g da amostra seca em balança analítica (BEL Engineering). A matéria prima foi colocada em papel filtro e este foi inserido no extrator do tipo Soxhlet, conforme metodologia descrita pelo Instituto Adolfo Lutz (2008). Adicionaram-se $130 \mathrm{~mL}$ de solvente, hexano ou etanol (Dinâmica LTDA) em um balão volumétrico de fundo redondo o qual foi acoplado ao sistema. A extração foi iniciada e o refluxo mantido por 60 e 120 minutos. O procedimento foi realizado conforme planejamento fatorial completo $2^{2}$ em duplicata e de forma aleatória, conforme Tabela 1.

\subsection{Evaporação}

Após a extração, os extratos foram coletados e levados a um evaporador rotativo (Fisatom modelo 550) para a eliminação dos solventes e em seguida as amostras foram pesadas e o rendimento calculado.

\subsection{Análise dos resultados}

Os resultados obtidos foram tratados no software Statistica7(StatSoft $\circledast$ ) e submetidos à análise de variância (ANOVA) a 95\% de confiança.

\section{RESULTADOS E DISCUSSÃO}

A Tabela 1 apresenta os resultados obtidos na extração através de um planejamento fatorial completo $2^{2}$. De acordo com a tabela, obtém-se maior rendimento na extração de 60 min usando etanol como solvente, apresentando em média 0,45 g de óleo para cada $3 \mathrm{~g}$ de semente, o que representa $15 \%$ de rendimento.

Tabela 1. Resultados da matriz de planejamento com valores reais e codificados.

\begin{tabular}{cccccccc}
\hline Ensaios & $\mathrm{X}_{1}$ & $\mathrm{X}_{2}$ & $\begin{array}{c}\text { Tempo } \\
(\mathrm{min})\end{array}$ & $\begin{array}{c}\text { Tipo de } \\
\text { Solvente }\end{array}$ & $\begin{array}{c}\text { Rendimento } \\
(\mathrm{g})\end{array}$ & Média $(\mathrm{g})$ \\
& & & 60 & Hexano & 0,07 & 0,05 & $0,06 \pm 0,01$ \\
1 & -1 & -1 & 120 & Hexano & 0,06 & 0,05 & $0,05 \pm 0,01$ \\
2 & +1 & -1 & 60 & Etanol & 0,48 & 0,43 & $0,45 \pm 0,04$ \\
3 & -1 & +1 & 120 & Etanol & 0,42 & 0,46 & $0,44 \pm 0,03$ \\
4 & +1 & +1 & & & & & \\
\hline
\end{tabular}


A partir dos dados obtidos do planejamento experimental determinaram-se quais os parâmetros são significativos para essa extração do óleo da semente da ameixa amarela (Tabela 2). Observou-se que apenas o solvente foi significativo, pois foi o único parâmetro que apresentou $\mathrm{p}<0,05$ (RODRIGUES, IEMA, 2005).

O tempo de extração não foi significativo neste estudo, ou seja, aumentar o tempo de extração de 60 para 120 min não aumenta o rendimento, por isto esta extração pode ser realizada em 60 min. Segundo Martins et al. (2015) a extração feita do óleo essencial da amêndoa de Butiá Capitata - fruta semelhante a ameixa amarela - onde foi variado o solvente (hexano e etanol) e tempo de extração (30 e $60 \mathrm{~min}$ ), apresentou maior rendimento no tempo de 60 min sendo equivalente a $38,80 \%$.

Tabela 2. Efeitos, erro padrão, t e p-valor para planejamento fatorial completo $2^{2}$.

\begin{tabular}{ccccc}
\hline Fatores & Efeitos & Erro padrão & $\mathrm{t}(6)$ & $\mathrm{p}$-valor \\
\hline Média & 0,2525 & 0,0084 & 29,7832 & 0,0000 \\
Tempo (1) & $-0,0100$ & 0,0169 & $-0,5897$ & 0,5870 \\
Solvente(2) & 0,3900 & 0,0169 & 23,0009 & 0,0000 \\
1 com 2 & $-0,0050$ & 0,0169 & $-0,2948$ & 0,7827 \\
\hline
\end{tabular}

Quanto ao segundo parâmetro avaliado, o uso de etanol como solvente demonstrou-se mais eficiente do que o hexano visto que o mesmo apresentou um rendimento maior, sendo um fator significativo para o estudo. O etanol, além de ser um solvente que vem de fontes renováveis, possui baixo custo e é facilmente encontrado. Além disso, por possuir ligações polares e apolares é capaz de purificar o óleo essencial, não levando consigo as ceras, parafinas e substâncias gordurosas que possam estar presentes nas sementes, obtendo assim um produto final puro e de consistência mais líquida (AZAMBUJA, 2009).

Com os resultados apresentados na Tabela 2, obteve-se o modelo codificado conforme a Equação (1), usando apenas os parâmetros significativos ao estudo. Onde $S=$ solvente.

$$
\text { Rendimento }(g)=0,2525+0,195 S
$$

Para determinar a qualidade do ajuste do modelo fez-se a análise da variância (ANOVA) demonstrada na Tabela 3. 
Tabela 3. Análise da variância (ANOVA) para o modelo codificado.

\begin{tabular}{llccc}
\hline $\begin{array}{l}\text { Fonte de } \\
\text { variação }\end{array}$ & $\begin{array}{c}\text { Soma dos } \\
\text { quadrados }\end{array}$ & $\begin{array}{c}\text { Graus de } \\
\text { liberdade }\end{array}$ & $\begin{array}{c}\text { Quadrado } \\
\text { médio }\end{array}$ & F $_{\text {calc }}$ \\
\hline Regressão & 0,3042 & 1 & 0,3042 & 715,76 \\
Resíduo & 0,0025 & 6 & $4,25.10^{-4}$ & \\
Total & 0,3067 & 7 & & \\
\hline
\end{tabular}

Coeficiente de determinação $\left(\mathrm{R}^{2}\right)=99,16 \%$

$\mathrm{F}_{1 ; 6 ; 5}=5,99$ (tabelado)

Conforme a Tabela 3, o valor do F calculado foi de 715,76 enquanto que o $\mathrm{F}$ tabelado apresentou 5,99, sendo assim o F calculado > F tabelado, ou seja, aproximadamente 120 vezes maior, considerando-se então que o modelo codificado é preditivo (BARROS NETO et al., 1995). De acordo com o coeficiente de determinação obtido, o modelo obtido neste estudo explica 99,16\% das respostas preditas pelo mesmo, sendo considerado por isto um ótimo modelo. Na Figura 1 estão apresentados os resultados das extrações do óleo da semente da ameixa amarela a partir e análise da superfície de resposta.

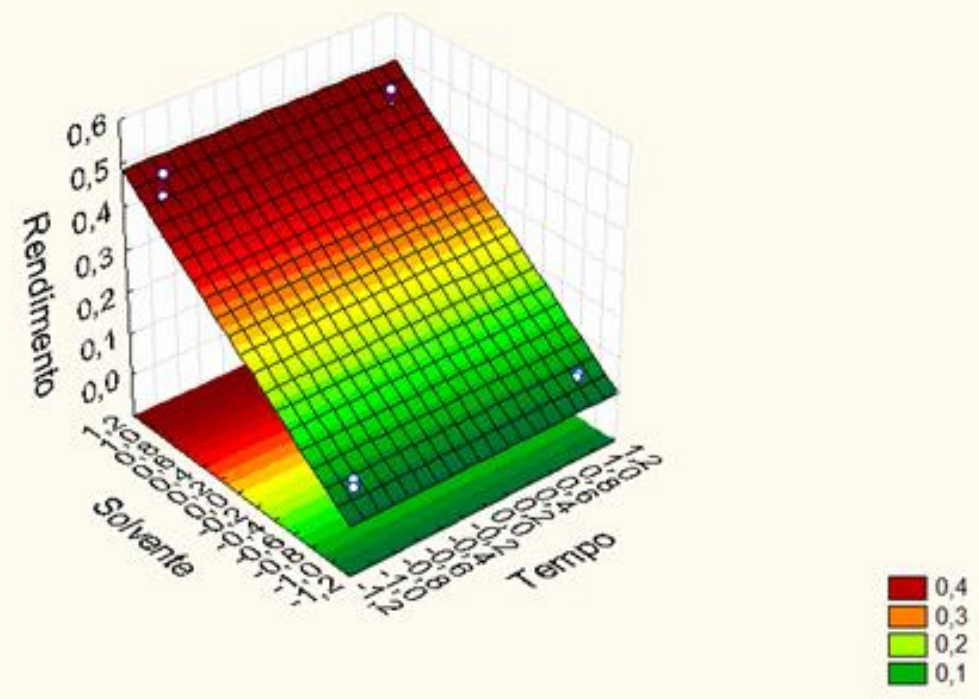

Figura 1 - Superfície de resposta para tempo (min) e diferentes solventes para a extração do óleo da ameixa amarela.

Observa-se na Figura 1 que o rendimento atinge seu maior valor para nível positivo (+) no eixo dos solventes e para todos os níveis do eixo do tempo, demonstrando que o melhor rendimento é com o etanol independente do tempo de 60 ou 120 min. Já o menor rendimento se obtém no nível negativo (-) do eixo de solvente e para todos os níveis do eixo do tempo alinhados nessa região, demonstrando que com o uso do hexano se tem o menor rendimento, independente do tempo. 


\section{CONCLUSÃO}

Através deste estudo pode-se concluir que a melhor condição para a extração do óleo da semente da ameixa amarela foi com o solvente etanol, independente do tempo de extração estudado, sendo que neste caso, opta-se pelo menor tempo, ou seja, 60 min. Nestas condições obteve-se $15 \%$ de óleo. Agregar valor à resíduos industriais é muito importante, tanto para o meio ambiente, lucratividade para as empresas, como para possíveis aplicações industriais, já que a semente da ameixa amarela não tem uso industrial.

\section{REFERÊNCIAS BIBLIOGRÁFICAS}

ALBRIGHT, P. O livro completo de terapias complementares: As mais conhecidas terapias alternativas para aliviar os males do dia-a-dia. São Paulo: Nobel, 1998. p. 160.

AZAMBUJA, W. Óleos essenciais. Paraná, 2009.

BAJAJ, Y. P. S. (Ed). Biotechnology in Agriculture and Forestry: Trees III. 16 ed. New York: Springer-Verlag Berlin Heidelberg, 1991. p. 62-75.

BARROS NETO, B.; SCARMINIO, I. S.; BRUNS, R. E. Planejamento e otimização de experimentos. 2 ed. Campinas: Ed. UNICAMP, 1995. 299 p.

BIZZO, H. R.; HOVELL, A. M. C.; REZENDE, C. M. Óleos Essenciais no Brasil: Aspectos gerais, desenvolvimento e perspectivas. Química Nova, v. 32, n. 3, p. 588-594, 2009.

GIDLUND, M. et al. Caracterização do estado de oxidação da lipoproteína humana de baixa densidade - LDL - por meio de técnicas de óptica não linear. São Paulo: IFUSP, 2008. p. 12.

GONSALVES, P. E. (Org). Medicinas Alternativas: Os tratamentos não-convencionais. 3 ed. São Paulo: IBRASA, 1999. p. 92-93.

HASEGAWA, P. N. et al. Chemical composition of five loquat cultivars planted in Brazil. Ciência e Tecnologia de Alimentos. Campinas, v. 30, n. 2, p. 552-559, 2010.

INSTITUTO ADOLFO LUTZ. Normas Analíticas do Instituto Adolfo Lutz: Métodos Químicos e Físicos para análises de alimentos. São Paulo: IMESP, v.1, 4.ed., 2008.

KOBA, K. et al. Effect of loquat (Eriobotrya japonica) extracts on LDL oxidation. Food Chemistry. London, v. 104, p. 308-316, 2007.

LIM, T. K. Edible Medicinal and Non-medicinal Plants: Fruits. 4 ed. New York: Springer, 2012. 
MARTINS, P. F. et al. Extração do óleo essencial da amêndoa do Butiá Capitata. In: CONGRESSO BRASILEIRO DE ENGENHARIA QUÍMICA EM INICIAÇÃO CIENTÍFICA, 2015, São Paulo. Anais... São Paulo: Unicamp, 2015. p. 2-5.

RICHARDS, A. Faça os seus próprios óleos essenciais a partir de plantas cruas: Usar Óleos e Ervas para uma Saúde Ótima. [S.1.]: Babelcube Inc., 2015. p. 9.

RODRIGUES, M. I.; IEMMA, A. F. Planejamento de experimentos e otimização de processos: uma estratégia sequencial de planejamentos. Campinas: Casa do Pão Editora, 2005. 325 p.

SMALL, E. Top 100 Exotic Food Plants. Canada: Taylor \& Francis Group, 2012. p. 357-360.

SOUZA, S. A. M.; MEIRA, M. R. Óleos Essenciais: Aspectos econômicos e sustentáveis. Enciclopédia Biosfera. Goiânia, v. 6, n. 10, p. 1-11, 2010. 